\title{
El uso de materiales visuales en la investigación histórico-educativa
}

\author{
Ian Grosvenor \\ School of Education \\ University of Birmingham \\ i.d.grosvenor@bham.ac.uk
}

Kate Rousmaniere

Miami University

rousmak@miamioh.edu

\section{Introducción}

La mayor parte de la investigación cualitativa está dominada por el lenguaje. Sin embargo, el deseo de crear imágenes ha existido a lo largo de la humanidad, desde las pinturas rupestres en el tiempo de las cavernas hasta las miles de millones de selfies que son tomadas cada año con dispositivos móviles. Usamos imágenes no sólo para representar el mundo que nos rodea, sino también para compartir nuestros sentimientos con otros, ya sea como memorial de un momento importante o para transmitir las emociones de ese momento particular. Hoy en día, el uso de la tecnología nos permite considerarnos fotógrafos documentales. De manera colectiva, esas imágenes son significantes de una cultura, de manera individual, son una evidencia de nuestra existencia y pueden ser analizadas como tal. En años recientes ha crecido el interés de algunos investigadores por usar imágenes para mejorar la comprensión de la condición humana, sin embargo, como plantea Cohen: "si los historiadores han oído hablar de este giro visual... lo han ignorado" (Cohen, 2003:251), por lo que lo visual mantiene un estatus menor que lo textual.

Hemos promovido el uso de los recursos visuales como parte de la práctica histórica dentro de nuestra investigación en la historia de la educación (Grosvenor, 1999; Rousmaniere, 2001), así en el 2014 fuimos invitados por el Cinvestav, en el marco del XI Congreso Iberoamericano de Historia de la Educación Latinoamericana, para organizar un taller de acercamiento al tema. El taller estuvo organizado en cuatro partes: Diálogos visuales, Construyendo significados, Cinco pasos para entender una fotografía y Dilemas éticos. En este escrito brindamos una reseña de las distintas actividades realizadas y temas principales que 
surgieron en la discusión. Si bien es cierto que la evidencia visual comprende un amplio espectro material (pinturas, dibujos, grabados, fotografías, cine y video), el taller se enfocó únicamente en la fotografía. A los participantes se les solicitó llevar al taller una fotografía que tuviera un significado personal para ellos.

\section{El taller \\ Primera parte. Diálogos visuales: conectando imágenes}

Los participantes se dividieron en grupos de cuatro, a cada grupo se le asignó el mismo conjunto de diez fotografías. Estas eran de carácter internacional, de múltiples periodos históricos, de educación formal o informal, sin ningún patrón común de lo que representaban. A cada grupo se le pidió elegir cuatro imágenes significativas, podían escogerlas bajo cualquier lógica o elemento en común que conectara las cuatro imágenes. Luego cada grupo mostró las imágenes elegidas a todo el conjunto y explicó las conexiones que encontraron entre ellas. También explicaron el proceso por el que llegaron a esa decisión.

Este ejercicio tenía tres objetivos: en primer lugar, romper el hielo; en segundo lugar, poner el tema visual en la mente de los participantes, y tercero, demostrar qué fácil es hacer distintas conexiones entre fotografías dada la naturaleza azarosa e inclusiva de las fotografías individuales.

\section{Segunda parte. Construir significados}

Continuación del ejercicio anterior, Se centró en las interpretaciones individuales y las perspectivas personales, principalmente en la construcción de un significado individual a través de una dinámica en parejas. Cada miembro de la pareja eligió la imagen que tenía significado para él; luego la intercambiaron sin decir nada sobre la imagen o el por qué del significado- El otro examinó la imagen y explicó por qué pensaba que era significativa para su compañero. Finalmente, el que eligió la foto debía responder.

\section{Tercera parte. Cinco pasos para entender una fotografía}

El objetivo era dotar a los participantes con una forma de trabajo sobre las imágenes que fuera transferible a otros contextos y contenidos. Se analizó una fotografía en grupo bajo el método de los cinco pasos de Tinkler (2013) y Grosvenor (1999). Primero, se estableció el lugar y tiempo de la fotografía, ¿Dónde ocurrió? ¿Existe alguna pista que delate cuándo fue 
tomada esta fotografía?; un segundo paso, analizó la forma y presentación de la fotografía, ¿Qué tipo de imagen era? ¿Se puede clasificar? ¿La clasificación afecta la naturaleza de la imagen?; como tercer paso, se revisó el Contenido, ¿Qué hay en la fotografía? ¿Cómo transmite el fotógrafo el contenido ? ¿Qué se está ignorando?; el cuarto paso consideró la materialidad de las fotografías y las imágenes, vistas como objetos materiales preguntando sí ¿existe evidencia de cómo ha sido usada la fotografía? ¿Es posible construir una biografía de la imagen? Finalmente, la construcción de significados, ¿Cuál fue la intención del fotógrafo? ¿Qué significado tuvo para un espectador de la época? ¿Qué significado tiene ahora?

Puntos clave

Las fotografías son objetos culturales, hechas para proyectar significados y provocar efectos. Incluso tienen un propósito y están en un contexto. Por lo tanto, podríamos considerarlas como momentos aislados y privilegiados dentro de un marco un momento en el tiempo, un momento privilegiado sobre otros que se han perdido.

Generalmente los sujetos fotografiados están conscientes de que están siendo fotografiados, de que son parte de una relación de intercambio, cuyo objetivo es el registro de la "normalidad". Sin embargo, el momento del registro también un momento de perturbación. El sujeto consciente de que lo que está ocurriendo, suspende las relaciones sociales normales para que sean fotografiadas. Se altera lo que se pretende registrar.

Tradicionalmente, los historiadores han usado las fotografías para extraer evidencia de la materialidad del pasado. Incluso cuando las fotografías son consideradas "azarosamente inclusivas"; es decir, cargan un exceso de información que "amenaza con volverlas ilegibles". En consecuencia, sus posibilidades son tan variadas que no pueden registrarse en una sola interpretación.

Si bien, el momento es capturado en luz y convertido en registro, es solo un fragmento de entre muchos momentos pasados perdidos. Dada su inclusividad, existe una conexión, más allá de lo que la fotografía registra, con otros momentos, sujetos, experiencias, historias, etc. También existe la posibilidad de que ese momento pueda manipularse en el proceso de impresión de la imagen o colocarse junto a otras imágenes o textos.

El significado está enmarcado en el contexto en el cual observamos la imagen pero resulta necesario examinar la vida de la imagen; considerar su circulación, su valor a través del tiempo y el espacio y de un contexto a otro (Walker, 1997). Las propiedades de una imagen no cambian, pero su existencia material acumula diferentes significados cuando entra en relación con nuevos contextos y públicos. Por ejemplo: una fotografía familiar o de una comunidad escolar rural en Brasil. 
Nos preguntarnos por la imagen misma, nos preguntamos por el viaje de la fotografía. Esta fue tomada por el fotógrafo británico Benjamin Stone (1838-1914), conocido por su valioso trabajo a finales del siglo XIX alrededor del mundo. La fotografía fue vista a finales de la década de 1990 por una investigadora norteamericana en el archivo de Birmingham, donde se resguardan los documentos de Stone; ella se llevó una copia a Estados Unidos. Ahora esa fotografía está exhibida en un taller en México en 2014.

En cada paso del viaje la fotografía será recontextualizada. Si cambia el contexto, cambia su significado.

Construir significado y derivar conocimiento histórico de una fotografía sólo es posible si se reconoce y entiende la intención del fotógrafo justo en el momento de la producción. Asimismo, es importante buscar alteraciones hechas para transmitir significados implícitos en la realidad capturada por la fotografía. Michel Foucault advirtió: "Never consent to being completely comfortable with your own certainties" (Foucault, 1997:144). La desventaja de una mirada experta consiste en que no pueda ver más allá. El conocimiento puede ser una barrera, una limitación para el flujo de significados. El conocimiento está acompañado por una forma particular de entendimiento. Como seres humanos no podemos ser excluidos de la identidad de lo que vemos, existe subjetividad en lo que miramos.

\section{Cuarta parte. Dilemas éticos}

Se presentaron una serie de imágenes de niños del archivo fotográfico del Museo Dr. Guislain en Gent, Bélgica. El museo se localiza en un hospicio de los Hermanos de la Caridad. Muchas imágenes las tomó el hermano Ebergist Gustaaf De Deyne (1887-1943), personaje representativo en el desarrollo de la educación especial en Bélgica, autor de L'éducation Sensorielle chez les Enfants Anormaux (1992), donde incluía muchas de sus fotografías. (Las imágenes están en Devlieger et al. (2008).

Puntos clave

Colectivamente, las imágenes muestran a la cámara, nueva tecnología, capturando la realidad. Era un mecanismo para la objetividad: se capturan momentos en filme. Así, las técnicas visuales definen y categorizan un texto de referencia que después resulta una herramienta en la educación para diagnosticar o predecir tendencias conductuales. Se trata de nuevas técnicas que producen nuevo conocimiento a través de nuevas tecnologías. Estas imágenes también generan problemáticas particulares. En un ensayo reciente sobre mirar y aprender en un salón de estudios de discapacidad, (Benin y Cartwright 2006) usan el concepto de vergüenza de Silvan Tomkin (Benin y Cartwright, 2006:156) para explorar una authorised 
public looking (mirada pública autorizada). La primera reacción al ver una imagen de cuerpos con discapacidades visuales implica una mirada hacia "afuera" y una mirada hacia "adentro". La imagen logra que el espectador transite de una incomodidad inicial a un compromiso crítico. Estas fotografías y la colección de la que forman parte se clasifican como imágenes documentales, no pretenden una buena impresión para atraer la atención del público a un determinado sujeto. La fotografía documental, en aras de la búsqueda de reforma, tiene el potencial de explotar al sujeto. Es crítico cuando no hay consentimiento del sujeto fotografiado (Sekula, 1984). El sujeto puede no haber dado su consentimiento o puede haberlo dado pasivamente (posando directamente para la cámara). Los investigadores en ciencias sociales se conducen por una serie de directrices éticas, pero ninguna directamente sobre el uso de fotografías en el trabajo histórico. Los historiadores han escrito muy poco sobre la ética en la fotografía. Hacer consideraciones acerca del derecho a la privacidad, es decir, que las personas controlen las imágenes de sí mismos y sus condiciones de uso, tiene dimensiones prácticas y de principio. En otras palabras, ¿Se pueden mirar fotografías para las cuales no hubo consentimiento informado? Si no se puede, al hacerlo ¿entramos en un voyerismo académico?

Frente a tales preocupaciones de índole documental se encuentra el propósito del fotógrafo. De Deyne tomó fotografías en un periodo en que los científicos las usaban para registrar y clasificar de seres humanos en términos médicos. Existen imágenes en que los elementos de utilería y los retratos resultantes se alejan del discurso médico y asemejan fotografías de estudio, así devuelven cierta dignidad al sujeto fotografiado. Las imágenes De Deyne se interpretan como refuerzo a la agenda "normalizadora" y como desafío a la misma. Cabe recordar que las imágenes son producto de un momento específico y su significado está relacionado con ese momento. Ya en el presente están totalmente separadas de ese contexto de entendimiento.

La ética también se conecta con la elección de una imagen sobre otra, ya que coloca al investigador en una posición de poder. El investigador decide lo que usa como evidencia y se presenta públicamente y lo que queda descartado.

\section{Quinta parte. La Revolución digital}

Consistió en una discusión abierta sobre las implicaciones de la revolución digital para la investigación visual.

Puntos clave

La digitalización permite un mayor acceso a los recursos visuales a través de internet. En los siglos XIX y XX, las fotografías han adquirido un aura de credibilidad. Sin embargo, las nuevas tecnologías de la imagen comprometen la credibilidad de las imágenes como fuente veraz.. 
Es una problemática de los investigadores comprometidos con el desarrollo de diálogos visuales. Al reemplazar la experiencia táctil por la lectura de imágenes en la pantalla, se puede decir que la digitalización ha provocado una sensación de pérdida, un distanciamiento del pasado. Los flujos de información distribuidos por internet implican que las significaciones emocionales y sensoriales de las fotografías se dispersan. Hay el contraargumento de que crear una versión digital de los álbumes implica nuevas prácticas sensoriales y corporales. Elizabeth Edwards ha escrito: "mirar en grupos alrededor de una pantalla, el dedo en el teclado, el deslizamiento del mouse, el cursor en la pantalla o los toques en la pantalla táctil han creado nuevos registros del tacto... este tipo de prácticas reubican las fotografías en espacios expandidos donde producen significados con un potencial de una gama muy amplia" (Edwards, 2010:32).

\section{Observaciones finales}

En resumen, en el taller atrajimos la atención hacia el potencial inherente en los recursos visuales para la investigación histórica y social. Todavía existe un gran número de investigadores escépticos de la utilización de lo visual, particularmente de fotografías.

La "estética oculta" de las fotografías, la teatralidad necesaria del encuadre, la orquestada coreografía inconsciente de cualquier agrupación, es muy significativa y hay que estar alertas a lo que Raphael Samuel Ilama: "quotation marks around old photographs" ("poner las viejas fotografías entre comillas”) (Sleight, 2016:17).

\section{Bibliografía complementaria}

Benin, David y, Lisa Cartwright (2006), "Shame, Empathy and Looking Practices: Lessons from a Disability Studies Classroom", Journal of Visual Culture, vol. 5, num. 2, agosto, pp. 155-171.

Devlieger, Patrick, Ian Grosvenor, Frank Simon, Geert Van Hove y Bruno Vanobbergen (2008), "Visualising disability in the past", Paedagogica Historica, vol. 44, núm. 6, diciembre, pp. 747-760.

Dussel, I. (2013), "The Visual Turn in the History of Education: Four Comments for a Historiographical Discussion", en Th. S. Popkewitz (ed.), Rethinking the History of Education. Transnational Perspectives on its Questions, Methods, and Knowledge, Palgrave Macmillan, Nueva York, pp. 29-49.

Edwards, Elizabeth (2010), "Photographs and history: emotion and materiality" en S. H. Dudley (ed.), Museum materialities: objects, engagements, interpretations, Abingdon, Routledge, pp. 21-38.

Foucault, Michel (1997), "For an ethics of discomfort" en Sylvére Lotringer y Lysa Hochroth (eds.), The politics of truth: Michel Foucault, Semiotex(e), Nueva York, pp. 135-145.

Grosvenor, Ian (1999), "Visualising Past Classrooms", en lan Grosvenor, Martin Lawn y Kate Rousmaniere (eds.), Silences \& Images: The Social History of the Classroom, P. Lang, Nueva York, pp. 83-104. 
Rousmaniere, Kate (2001), "Questioning the visual in the history of education", History of Education, vol. 30, núm. 2, noviembre, pp. 109-116.

Sekula, Allan (1984), Photography Against the Grain: Essays and Photo Works, 1973-1983, Nova Scotia College of Art and Design, Halifax.

Sleight, Simon (2016), Young People and the Shaping of Public Space in Melbourne, 1870-1914, Routledge, Londres.

Tinkler, Penny (2013), Using Photographs in Social and Historical Research, SACE, Londres.

Walker, John (1997), "Context as a Determinant of Photographic Meaning", en J. Evans (ed.), The Camerawork Essays, Rivers Oram Press, Londres, pp. 52-63. 